ARTICLE

DOI: $10.1057 / \mathrm{s} 41599-018-0124-6$

\title{
What makes people approve or condemn mind upload technology? Untangling the effects of sexual disgust, purity and science fiction familiarity
}

\author{
Michael Laakasuo ${ }^{1}$, Marianna Drosinou ${ }^{2}$, Mika Koverola ${ }^{1}$, Anton Kunnari ${ }^{2}$, Juho Halonen ${ }^{1}$, Noora Lehtonen ${ }^{1} \&$ \\ Jussi Palomäki ${ }^{1}$
}

\begin{abstract}
The idea of separating a person's consciousness and transferring it to another medium-'mind upload'-is being actively discussed in science, philosophy, and science fiction. Mind upload technologies are currently also being developed by private companies in Silicon Valley, and similar technological developments have received significant funding in the EU. Mind upload has important existential and ethical implications, yet little is known about how ordinary people actually feel about it. The current paper aims to provide a thorough moral psychological evaluation about various cognitive factors that explain people's feelings and reactions towards the use of mind upload technology. In four studies (including pilot) with a total of 952 participants, it was shown that biological and cultural cognitive factors help to determine how strongly people condemn mind upload. Both experimental manipulations in a laboratory and cross-sectional correlative online study designs were employed. The results showed that people who value purity norms and have higher sexual disgust sensitivity are more inclined to condemn mind upload. Furthermore, people who are anxious about death and condemn suicidal acts were more accepting of mind upload. Finally, higher science fiction literacy and/or hobbyism strongly predicted approval of mind upload. Several possible confounding factors were ruled out, including personality, values, individual tendencies towards rationality, and theory of mind capacities. Possible idiosyncrasies in the stimulus materials (whether consciousness is uploaded onto a computer, chimpanzee, artificial brain, or android; and whether the person's body physically dies during the process) were ruled out. The core findings inform ongoing philosophical discussions on how mind upload could (or should) be used in the future, and imply that mind upload is a much more salient topic for the general population than previously thought.
\end{abstract}

\footnotetext{
${ }^{1}$ University of Helsinki, Faculty of Arts, Department of Digital Humanities, Cognitive Science, Helsinki, Finland. ${ }^{2}$ Department of Psychology, University of Helsinki, Faculty of Medicine, Helsinki, Finland. Correspondence and requests for materials should be addressed to J.P. (email: jussi.palomaki@helsinki.fi)
} 


\section{General introduction}

'Somehow [there was something] deeply disturbing: disgust that arose from the conjunction of two ostensibly irreconcilable systems of imagery, that of flesh and that of machinery'

Mark O'Connell in 'To be a Machine' (p. 89), describing the implementation of mind upload technologies

lmost all human cultures throughout history seem to have developed religious or moral sanctions and norms on how the souls and spirits of people are allowed to transfer, move, and operate in the world. Since ancient Egypt, humans have certifiably been concerned with moral issues related to the fate of their souls (Mark, 2016). How humans treated themselves and others influenced the quality and the value of their souls: In ancient Egyptian mythology the soul's value (i.e., the heart) was weighted against a feather in the Judgment hall of Osiris, before entering afterlife (Mark, 2016).

Similar concerns were also later apparent in Greek mythology, where souls, as well as living heroes, could end up in Hades/ Erebus if the mortals angered the Olympian gods. However, only exceptional heroes could make their way back from the underworld while most mortals and their souls could not. For example, in book 11 of Odyssey (Homer and Rieu, 1959), Odysseus himself participates in a rite of Nekyia to travel to the Underworld to meet the spirit of Teiresias and to communicate with him about returning home. Social concerns in earthly life were also apparent in ancient Greek religions (McEvilley, 2002), particularly in Orphism, where the purity of the soul influenced the trials that it would go through in the afterlife (McEvilley, 2002; Petrovic and Petrovic, 2016). In Plato's writings the purity of the soul and concerns regarding its development are discussed extensively (McEvilley, 2002; Zeyl, 2009) either by Socrates in espousing his philosophical arguments (Edmonds, 2015; e.g., Phaedo and Republic); or when reflecting on the Orphic mystery cult (Parker, 1995).

Later on, the theological ideas about the soul were copied from Neoplatonism (mediated through Judaism; Wright, 2009) to the budding constructions of the Catholic canon; and under Christianity, moral concerns in the communal life governed the fate of the individual's soul (Carrier, 2014). In ancient India too, individuals' social and moral lives were intertwined with their afterlife narratives in Buddhism and in Hinduism (Jürgensmeyer and Roof, 2011). These concerns about the soul are often connected with norms governing ritualistic purity (Douglas, 1966); and the norms and their upkeep, in turn, seem to be motivated by the emotion of disgust (Rozin et al., 1999). ${ }^{1}$

In cognitive anthropology and evolutionary psychology, one of the basic assumptions is that if some cultural phenomenon or certain forms of socio-epistemic patterns ('memes' or 'social representations') are universally-or near universally-found across our globe and shared between ethnicities, there most likely is a biological component involved (Boyer, 2001; Bering, 2006; Moscovici, 2001; Tooby and Cosmides, 2005; see Sperber, 1996 for epidemiology of ideas). Indeed, anthropological evidence suggests that moral beliefs and attitudes concerning souls could pre-date even ancient Egypt (Wright, 2009; Frazer, 1922; Tylor, 1974; Durkheim, 1915). Most likely the cognitive mechanisms involved here are those that relate to regulating communal living boundaries (Wilson, 2002) and awareness of in-group norm purity, disgust mechanisms (Curtis, 2013), as well as mechanisms related to Theory of Mind capacities (Bering, 2006; Boyer, 2001).

Since the beginning of ethnographic research, evidence has accumulated on hunter-gatherers and their varied conceptions of souls and spirits (Eliade, 1964). According to Émile Durkheim
(1915), spirits can disparate from the bodies of witches during night and commit crimes and mischief. If the witches are caught they can be punished by the surrounding community. Anthropologists studying Latin American shamanism have also reported that it is common for shamans in these cultures to be feared, because they reportedly have skills of traveling in the spirit world and transforming into animals (Narby, 2005).

The mythological theme and narrative of individuals' spirits traveling to other worlds and into various other bodies or entities is also found in Siberian shamanism (Anttonen, 1994), various African tribes,!Kung San Bushmen, and various schools of Candomble (Johnson, 2002). Sometimes these spirit travels are accepted, sanctioned, and even positively welcomed by the communities; other times, in different alternative contexts, the soul's traveling into animals or different realms is forbidden, feared, and only allowed for the experts, such as the local psychopomps (Eliade, 1964; Anttonen, 1994; Boyer, 2001; Narby, 2005).

In summary, moral sanctioning and rule setting on how spirits or souls are allowed to transfer, move, and operate in the world has been a relatively universal phenomenon throughout human history; as seems to be its connection to ritualistic aspects of human social life (Douglas, 1966).

Cognitive science and developmental psychology have extensively researched folk psychology and more or less established that humans are so called intuitive substance dualists-we instinctively separate mind from matter in our everyday lives (Bering, 2006; Bloom, 2004). Furthermore, the fact that the fate of the soul is very often connected to social issues and rules indicates that human intuitive substance dualism has either been exapted to serve social functions; or has some hitherto unrecognized evolutionary pressures behind it (Wilson, 2002; Haidt, 2007).

Whether souls actually exist or not is not our primary concern; but we (humans) nonetheless have intuitions about souls and their ritual purity. Moreover, these purity intuitions regarding the soul are almost universally animated by the emotion of disgust (Bering, 2006; Haidt, 2006; Rozin et al., 1999; Douglas, 1966). Intuitions about the soul are pervasive in modern times as well (Bloom, 2004; Bering, 2006). The theme of soul transfer is visible in modern contexts, such as tech-companies in Silicon Valley promising to transfer our minds unto silicon-based mediums $\left(\operatorname{see}^{2} ;\right.$ and $\left.^{3}\right)$, and postmodern contexts in science fiction films as Chappie (2015) or Transcendence (2014). This perennial theme in our history keeps gripping our imaginations and arresting our attentions. Still, the science fiction-esque nature of these issues makes some feel that this technology and the ethical concerns related to it are not urgent or relevant for at least the next 20 years or so (see Bostrom, 2014 for discussion). As a counterpoint, we note that a copy of a C. elegans' nervous system has already been placed inside a robot ${ }^{4}$, and a functional copy of part of a rat's brain has been digitalized ${ }^{5}$. In both of these cases, the copy functions similarly to the original. Due to the exponential development speed of digital technologies (e.g., Bostrom, 2014; Tegmark, 2017), we might be facing the actuality of these technologies sooner or later. Thus, we feel that an informed scientific discussion regarding these matters is called for, well in advance.

However, modern research has not thoroughly investigated our moral intuitions in conjunction with soul transfer. Recent studies have explored the implications of perceiving artificial intelligences (AIs) as moral agents, such as in the case of self-driving cars (Bonnefon et al., 2016; Ward et al., 2013 a further preliminary work suggests that theory of mind capacities might be involved in moral cognition relating to AIs (Ward et al., 2013; Waytz et al., 2010; Gray et al., 2012). Modern day information processing technologies are complex and being constantly applied to new areas of human action. Nonetheless, most areas of human 
behaviour involving moral decision making, such as rescue operations, prioritizing medical cues or implementing life extension technologies, have received little attention in experimental philosophy and studies of moral cognition. We aim to widen the scope of this new emerging field concerning the morality of intelligent machines with our series of studies.

Robots and AIs are becoming more intelligent, autonomous and capable. It is thus important to understand how our moral cognition functions in interaction with them (Wallach and Allen, 2008). According to recent theoretical developments, it has been suggested that modern AI technology is giving birth to a 'new ontological category': social agents that are not alive, yet function as if they were (Severson and Carlson, 2010). This might pose a fundamental challenge for our stone-aged cognitive apparatus that evolved during the Pleistocene era when inanimate objects did not come to life and interact with us (Tooby and Cosmides, 2005). An example of this in modern societies is when humans are treating their robot pets as if they were real pets (Melson et al., 2009). In other words, robots and AIs are a new category that is fundamentally at odds with our natural cognitive human categories (for discussion on natural categories, see Atran, 2002). Therefore, human interaction with new technologies needs to be investigated from a moral cognitive perspective, since autonomous moral agents or AMAs (Wallach and Allen, 2008) and other forms of new technologies create unprecedented moral dilemmas and situations that cannot be understood from the perspective of old paradigms and theories. In a sense, we are starting to operate in a world of moral zombies; how our 'tribal monkey moral minds' (Haidt, 2012; Greene, 2014) interact with new technologies is an intriguing scientific problem.

These issues are relevant not just for science fiction stories and new budding forms of moral psychology. Recently, themes relating to soul transfer or mind upload have received extensive attention also in philosophy of science and philosophy of mind (Cappuccio, 2017; Pigliucci, 2014; Chalmers, 2010). Mind upload technologies are seriously discussed in a very detailed manner, since the scientific and philosophical issues related to these technologies sit elegantly at an epistemic hub between different schools of thought in consciousness studies, as well as embodied -and classical cognitive sciences (Cappuccio, 2017). These technologies are being taken seriously enough to be investigated by even The U.S. President's Council on Bioethics, whose chair Leon Kass condemned their development and use by openly appealing to his emotion of disgust (see O'Connell, 2017, p. 37).

We therefore decided to investigate the connections between these dualistic intuitions, disgust sensitivity and moral sanctioning of soul transfers within the post-modern cultural context. More specifically, we evaluated how a wide array of individual difference measures and situational factors influence moral condemnation in scenarios where a scientist uploads his mind (consciousness) onto a computer (or other medium). We did not have any specific hypotheses in the beginning; these studies were purely exploratory. In this case, forming hypotheses based on preexisting theory should come after the phenomenon itself has been investigated more carefully. However, gaining new knowledge in our intuitions about mind upload deepens our understanding of several different fields of inquiry. We will return to these issues in the General Discussion section.

\section{Data analyses}

In all our studies, we analyzed our data using multiple regression models. In other words, we employed several independent (explanatory) variables to explain the variability within our dependent (response) variable (DV; approval/disapproval of mind upload technology). Multiple regression allows for evaluating how a number of different independent variables influence approval or disapproval of mind upload, while statistically controlling for the effects of the individual variables. This helps us deduce which of the independent variables are more relevant than others in terms of statistical significance and effect size. Across our studies we have constructed several multiple regression models, progressively increasing the number of independent variables, and then dropping the non-significant variables out (as per the principle of statistical parsimony).

\section{Pilot study}

The aims of the pilot study were to test our experimental paradigm and dependent variables. However, we did also expect to find a positive association between theory of mind (ToM) capacities and condemnation of mind upload scenarios (Ward et al., 2013). Furthermore, since the theme of uploading one's consciousness to a silicon-based medium is often discussed and associated with 'rationality activists' clustering around the popular blog LessWrong ${ }^{6}$ we included (as exploratory measures) two scales assessing individual variation in tendencies towards rationality. ${ }^{7}$ We also included the Moral Foundations Questionnaire (MFQ; Haidt and Graham, 2007), which is the most widely used psychometric tool assessing individual differences in moral preferences. Finally, we included measures on perceived vulnerability to diseases (PVD; Duncan et al., 2009), because some elements in our study vignettes (i.e., nano-machines) could be perceived as alien disease vectors (for details, see the story description below and Appendix SI Text 1 for the full version). Another reason to include PVD was a recent study showing a strong link between PVD and the MFQ Purity scale (Laakasuo et al., 2017); the PVD scale might thus have relevance to moral cognition in other contexts as well.

\section{Method}

Ethics statement. All local laws regarding ethics for social science research were followed in full in all studies. All participation was fully voluntary and participants were informed about their right to opt out at any point without penalties. Materials used and a study protocol were reviewed and approved by the University of Helsinki Ethical Review Board in Humanities and Social and Behavioural Sciences.

Participants and design. In total, 268 participants recruited through Amazon Mechanical Turk (MTurk) successfully completed a correlational questionnaire prepared with Qualtrics $(N=$ 268; 161 female; $\mathrm{Age}_{M}=31.63 ; \mathrm{SD}=10.92$; Range $=18-72$ ). All participants were US residents, and compensated US $\$ 1.50$. The median income of our participants was in the range of $\$ 40$ 000-45 000. Our participants reported their socio-economic status level (SES) using an 9-point scale ladder indicating how they felt they were positioned with respect to other Americans in overall education, income, and status $(M=5.00, \mathrm{SD}=1.58)$. Of our participants, 139 had obtained at least a Bachelor's degree. Research has shown that the quality of data gathered using MTurk is of no less quality than studies ran in laboratory environments (Horton et al., 2011; Paolacci et al., 2010).

Procedure and materials. Participants first gave informed consent and then filled in scales in the following order: Reading the Mind in The Eyes Task (Baron-Cohen et al., 2001), MFQ (Haidt and Graham, 2007), Three Domain Disgust Scale (Tybur et al., 2009), Religiosity Scale (see description below) and Science Fiction Hobbyism Scale (manuscript in preparation). Thereafter the participants read a story about a scientist who successfully transfers his consciousness (uploads his mind) onto a computer. 
The story was modeled after a description sketched by Hans Moravec (1988).

In the story, the scientist injects himself with nano-machines that enter his brain and substitute his neurons one-by-one. After a neuron has been substituted, the functioning of that neuron is copied (uploaded) on a computer; and after each neuron has been copied/uploaded the nano-machines shut down, and the scientist's body falls on the ground completely limp. Finally, the scientist wakes up inside the computer.

After reading the story the participants responded to the dependent variables, which were shown on the same page as the story (the participants could refer back to the story if needed). Finally, the participants answered demographic and other background questions, and were debriefed and thanked.

Reading the mind in the eyes (RMET) task. This task was developed by Baron-Cohen and colleagues (2001), and is usually employed as a measure of individual ToM capacity. ToM capacity predicts empathetic behaviour and the ability to take another person's perspective. The task consists of 32 close-up pictures of people's eyes portraying an emotion. Participants are given four options of emotion words to choose from, only one of which is the one that actually corresponds to the emotional tone of the eyes. Higher scores indicate higher theory of mind capacity, or empathizing ability (the scores also work as a performance measure of emotional intelligence).

Perceived vulnerability to diseases (PVD). The PVD scale measures individual differences in disease sensitivity (Duncan et al., 2009), and has two sub-scales: Perceived Infectability and Germ Aversion. Both sub-scales ask participants to rate how well a set of sentences describes them, on a scale from '1' (not at all) to '7' (very well). Perceived Infectability correlates with health-related anxieties and hypochondria. It is related to future fears of being ill and is specific to infectious diseases, but not to current or past health concerns (Duncan et al., 2009). It correlates with rational beliefs and predictions related to pathogens. For instance, individuals with immune system deficiencies (e.g., the elderly) typically score high on the scale. An example item is: 'If an illness is "going around", I will get it'. The scale has three reverse coded items (e.g., 'My immune system protects me from most illnesses that other people get.'). The Perceived Infectability sub-scale had good internal reliability (7 items, $\alpha=.90$ ). Higher scores indicate higher perceived infectability.

Germ Aversion measures individual anxiety related to situations with elevated risk of pathogen transmission. The scale correlates with disgust sensitivity and is related to intuitive assessment of perceived risks of contracting a disease in social settings. Individuals with high germ aversion intuitively avoid people with morphological abnormalities. An example item is: 'It really bothers me when people sneeze without covering their mouths'. The scale has three reverse coded items (e.g., 'My hands do not feel dirty after touching money.'), and had a satisfactory internal reliability in our sample ( 8 items, $\alpha=.79$ ). Higher scores indicate higher germ aversion.

Moral Foundations Questionnaire (MFQ). The MFQ measures individual variation in the foundations of 'intuitive ethics' (Graham et al., 2011). It is based on a model for five separate moral foundations: care/harm, fairness/cheating, loyalty/betrayal, authority/subversion, and sanctity/degradation. The MFQ has two parts. In the first part, the respondent is asked to rate how relevant various considerations (16 in total) are when deciding whether something is right or wrong, on a scale from ' 1 ' (not at all relevant) to ' 7 ' (extremely relevant). Example items are 'Whether or not someone suffered emotionally' (care/harm), and 'Whether or not someone violated standards of purity and decency' (sanctity/degradation). In the second part, the respondent rates his/her agreement with 16 statements on a scale from ' 1 ' (strongly disagree) to '7' (strongly agree). Example items are 'Compassion for those who are suffering is the most crucial virtue' (care/harm), and 'Chastity is an important and valuable virtue' (sanctity/ degradation). High (or low) scores on specific sub-scales indicate high (or low) relevance for said sub-scale in an individual's intuitive moral foundation or 'code of conduct'. The Cronbach's alpha values for all sub-scales were .69 for harm/care, .64 for fairness/cheating, .73 for loyalty/betrayal, .73 for authority/subversion and .80 for purity/sanctity.

Science Fiction Hobbyism Scale. This scale is currently under development. It consists of 12 items and measures individuals' cultural exposure to various science fiction themes. It has items such as 'I consider myself a major consumer of science fiction' and 'I think science fiction is an interesting topic'. All the questions were anchored from '1' (strongly disagree) to '7' (strongly agree). Higher scores indicate higher science fiction hobbyism and exposure to science fiction themes. In the current sample, the scale had good psychometric properties (all factor loadings > .57; Cronbach's alpha $=.92$ ). For full statistics and a listing of the scale items, see Appendix Tables A5-A8.

Religiosity Scale. We created this scale by compiling together 15 items. The scale measures individual differences in level of personal religious practice and commitment (see Appendix for detailed psychometric validation). Participants were shown statements and asked to evaluate their importance in their lives on a scale from '1' (not at all important) to '7' (very important). Example items are: 'Praying regularly' or 'Belonging to church or some other religious persuasion'. The scale had excellent internal consistency (Cronbach's alpha $=.96$ ). Higher scores indicate higher levels of religiosity (for full listing of items and further psychometric analyses, see Appendix Tables A9-A11).

Rational-experiential inventory (REI). The REI measures individual dispositions in two distinct thinking styles (Pacini and Epstein, 1999). The questionnaire consists of two orthogonal subscales labelled Rational and Experiential. Both sub-scales have 20 items and had excellent internal consistencies in our sample (Cronbach's alphas $=.91$ and .93 for Rational and Experiential, respectively). All items were anchored from '1' (strongly disagree) to ' 7 ' (strongly agree). The Rational sub-scale measures engagement in and enjoyment of cognitive activities, with higher scores indicating greater engagement and enjoyment. The Experiential sub-scale is the 'intuitive' counterpart of the Rational sub-scale, and measures faith in and reliance on initial impressions, with higher scores indicating greater faith and reliance. The REI has such items as 'I have no problem thinking things through carefully' (Rational) and 'I like to rely on my intuitive impressions' (Experiential). About half of the items in both sub-scales are reverse-coded, including 'Thinking is not my idea of an enjoyable activity' (Rational) and 'If I were to rely on my gut feelings, I would often make mistakes' (Experiential).

Dependent variable/disapproval of mind upload. Our dependent variable consisted of 10 items, which were averaged together. Eight of the items were anchored from '1' (completely disagree) to '7' (completely agree), for example: 'I found the scientist's actions to be irresponsible' and 'What the scientist did should be illegal'. One of these eight items was reverse coded (The scientist who makes progress in developing technologies like this should be rewarded). Two items were anchored from ' 1 ' (not at all) to '7' (very much): 'How immoral did you find the scientist's actions to 
be?' and 'How acceptable did you find the scientist's actions to be?'. The DV had a strong single factor structure and acceptable internal consistency (Cronbach's alpha $=.89$ ). Higher scores indicate higher rates of disapproval of mind upload technologies (for full details of the items and psychometric analyses in our pilot study see the Appendix Tables A1-A4).

Pilot study Results. We ran a multiple regression analysis by first building a baseline model with age and gender as covariates; and then sequentially adding covariates as follows. Second model: level of education and socioeconomic status. Third model: Religiosity Scale and Science Fiction Hobbyism scale. Fourth model: Reading the Mind in the Eyes task. Fifth model: Moral Foundations Questionnaire as a whole. Finally, in the sixth and seventh models we sequentially dropped all non-significant covariates (for full statistics see Table 1).

Our results suggest that cultural factors play a significant role in understanding the condemnation of mind upload: the scales measuring religiosity and science fiction hobbyism were strong predictors of disapproval and approval of mind upload, respectively (Models 3-7). Interestingly, level of education, SES, gender, and the RMET were not associated with condemning the scientist's actions in the story.

Surprisingly, two sub-scales from the MFQ were associated with approval and disapproval of the events described in the story (Fairness and Purity; Model 5). However, after removing nonsignificant variables from the analysis, only Purity remained statistically significant (together with science fiction hobbyism and religiosity; Models 5-7).

Additional pilot study analyses. Laakasuo et al. (2017) suggested that the PVD scale produces similar results in intergroup altruistic helping situations than the MFQ Purity sub-scale. In our exploratory analysis we entered both of the PVD sub-scales into the same analysis (see Table 1, Model 7); however neither of the PVD sub-scales were statistically significant predictors (Bs $<0.1$, | $\mathrm{t} \mid<1.2, p s=\mathrm{n} . \mathrm{s}$.). This suggests that, in the story, the nanomachines being injected in the scientist's bloodstream were not considered as disease vectors by our participants, and that in this context PVD has no relevance for moral cognition.

Some visible advocates for mind upload technologies are clustered around a popular online community called LessWrong (www.lesswrong.com). In this community the main focus point is in increasing the potential for human rationality and rational action. We therefore evaluated whether or not the approval of mind upload technology is related to individual differences in rationality-related thinking styles. We entered both $\mathrm{REI}^{8}$ scales into the analysis without any other variables, but only the Rationality sub-scale was statistically significant $(B=-0.19,95 \%$ CI $[-0.34,-0.04], p=.01)$. Further probing, however, revealed that the effect disappeared after entering the MFQ Purity variable into the analysis. This analysis suggests that rationality does play a role in adopting a positive attitude towards mind upload technology, but the effects are probably dependent on deeper cognitive structures associated with Purity orientations, which, in turn, are associated with the emotion of disgust. Thus, low levels of individual disgust sensitivity -instead of high levels of rational thought-might explain the approval of mind upload (see Studies 2 and 3 ).

Pilot study Discussion. The results of our pilot study indicate that the stimulus material is appropriate to study condemnation of mind upload. Higher religiosity was associated with higher levels of condemnation, whereas higher levels of science fiction hobbyism - which are culturally relevant factors-were associated

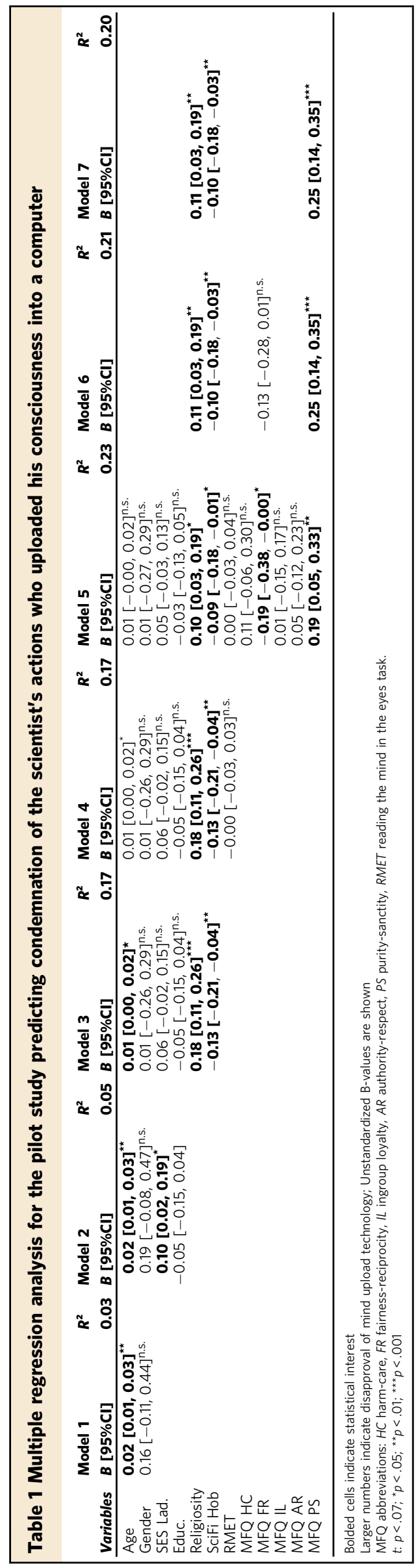


with higher levels of acceptance of mind upload technology, when both variables were included in the same model simultaneously.

The central implications of the Pilot Study are: (1) cultural factors seem to be very important for the formation of attitudes related to the approval or disapproval of mind upload technology, and (2) given the independent link between condemnation of mind upload and MFQ Purity, even after controlling for religiosity and science fiction hobbyism, the emotion of disgust might also be implicated in the current setting. MFQ Purity has been associated with the emotion of disgust in several recent studies (Laakasuo et al., 2017; Chapman and Anderson, 2014), and it is consistently associated with moral concerns in other domains as well. However, our exploratory analysis seems to imply that these attitudes for condemning mind upload are not related to pathogen components of disgust (PVD), but possibly to more abstract forms of disgust sensitivity; we return to this question in Study 2. The results also alluded to a link between the MFQ Fairness-Reciprocity sub-scale and condemnation of mind upload; however, we could not replicate this effect (see subsequent Studies) and therefore concluded it was probably a false positive (there were 12 variables included in the analysis, and the probability of finding at least one false positive, with the $p$ $=.05$ criterion, is $1-0.95^{\wedge} 12=\sim 46 \%$ while the expected number of false positives with 12 variables is $0.05^{\star} 12=0.6$ ).

Surprisingly, there were no associations between RMET scores and condemnation of mind upload. This implies that while ToM capacities might be necessary for us to form intuitions about souls and spirits, ToM alone is unrelated to the moral condemnation of uploading one's mind onto a different platform (for similar findings in context of supernatural beliefs, see Lindeman et al., 2015).

\section{Study 1}

After establishing the basic functionality of our vignette, study design and variables in an American Mturk sample, we sought to examine situational factors in mind upload scenarios in a laboratory experiment in Finland. Previous studies have established that people very easily dehumanize others who are different and associate them with less than human qualities (Haslam and Loughnan, 2014). Thus, perhaps the nature of the "target", where the scientist's consciousness was uploaded to, would explain some variance in people's attitudes towards mind upload technologies. We modified our original vignette by changing the target of mind upload to be either (1) a computer, (2) an android body, (3) a chimpanzee, or (4) an artificial brain. We reasoned that since similarity breeds familiarity, which, in turn, breeds acceptance, there could be more tolerance for transferring one's consciousness to an android body or to a chimpanzee compared with artificial brains or a computer.

In this study we also sought to explore whether fundamental personality factors in the HEXACO model of personality (Ashton and Lee, 2007, 2009; Lee and Ashton, 2004) or Schwartz's value orientations (Schwartz, 2003) play a role in condemning mind upload.

\section{Method}

Participants and design. In total, $160(N=160 ; 73$ female $)$ participants $\quad\left(\mathrm{Age}_{M}=39.76 ; \quad \mathrm{SD}=15.18 ; \quad\right.$ Range $\left.=18-75\right) \quad$ were recruited from a large public library in the city of Espoo and told they could participate in a study taking about $35 \mathrm{~min}$ of their time. Of the participants, 97 had at least a Bachelor's degree.

After a non-intrusive recruitment procedure (see below) the participant was escorted into our 'pop-up' laboratory located in the library. The participant then sat in front of a laptop computer, which randomized him/her into one of four conditions (the experimenters were blind to the randomization): The scientist in the story uploaded his mind into either (1) a computer, (2) an android body, (3) chimpanzee or (4) an artificial brain. As compensation, the participants were offered a chance to participate in a lottery for movie tickets (worth $24 \times 10 €$ ).

Procedure and materials. The data were gathered in a large public library in the Helsinki Metropolitan area. Participant recruitment was non-invasive: We had positioned a desk in the foyer area of the library, along with a sign stating: 'Participate in Psychological Research'. Research assistants dressed in neutral ordinary clothing sat behind the desk. All recruited participants approached our research assistants voluntarily. After making sure the participant was over 18 years old, they were given an informed consent form, telling them about the general purpose of the study and their right to opt-out at any point. After giving their signed consent, the participants were escorted into a laboratory space specifically set up for the purposes of this study.

The laboratory had four laptop computers with 15 " screens positioned in a way that guaranteed maximum privacy. The laboratory space was divided by office walls, and participants were instructed to use headphones playing pink noise to cover up any possible distracting noise. The pink noise volume was held constant at a pleasant level. The experiment was programmed using Python's Social Psychology Questionnaire library (Laakasuo, in preparation), which is built on top of Pygame version 1.96.

The experiment itself started by randomizing the participant into one of the four conditions listed previously. Both the experimenters and participants were blind to the randomization. Participants first filled in the HEXACO and Schwartz's Value scales, after which they proceeded to fill in the same Science Fiction Hobbyism and Religiosity scales used in the Pilot Study. Finally, the participants read one of the four vignettes/stories, where the scientist transfers his consciousness into either (1) a computer, (2) an android body, (3) chimpanzee or (4) an artificial brain. In all other respects, the story was identical to the one presented in the Pilot Study. After reading the story, the participants gave their responses to the dependent variables and demographic variables. Finally, they were debriefed and thanked by the research assistants.

HEXACO-60 personality inventory. We used the HEXACO-PI-R (also known as HEXACO-60; Ashton and Lee, 2009) to assess personality. HEXACO is a six-dimensional instrument with very good psychometric properties in personality assessment (Lee and Ashton, 2004; Ashton and Lee, 2007). It is highly similar to the Big Five or Five Factor Model constructs, with the exception of having an additional dimension labeled 'Honesty-Humility'. The Honesty-Humility dimension measures individual lack of interest in manipulating others for personal gain, and disinterest in status symbols and/or luxurious life style (Cronbach's alpha $=.77$ ). The other dimensions of HEXACO are Emotionality (Cronbach's alpha $=.73$ ), the tendency to experience fear, anxiety, and need of assurance; eXtroversion (Cronbach's alpha $=.82$ ), the tendency to experience positive feelings of enthusiasm and energy; Agreeableness (Cronbach's alpha $=.76$ ), the tendency to be forgiving, lenient, flexible and patient; Conscientiousness (Cronbach's alpha $=.70)$, the tendency to stay organized, control one's impulses and aspire for perfection; and Openness to Experience (Cronbach's alpha $=.78$ ), the tendency to be creative, curious, imaginative and appreciative of aesthetics. All items were anchored from '1' (strongly disagree) to '7' (strongly agree).

Schwartz's value inventory. We used the Portrait Values Questionnaire with 21 items (PVQ-21) as used in the European Social Survey, which measures ten basic values, e.g., Power, 
Universalism and Hedonism (Schwartz, 2003). Each item describes a person in terms of what is important to them (him or her; sample item for the value Self-Direction: 'Thinking up new ideas and being creative is important to him. He likes to do things in her own original way'). Respondents reveal their own values indirectly by indicating how much the person in each item is similar to them, from ' 1 ' (not at all like me) to ' 6 ' (very much like me). Individuals' scores for the importance of each value are their mean responses to the relevant items. Cronbach's alphas for the different basic values in different societies typically range from .30 to .80 and for the aggregate higher-order values from .65 to .80 .

Religiosity Scale. We used the same version of the scale as in the Pilot Study, with the exception of removing two items (ReversedHeywood cases in exploratory factor analysis that explained $0 \%$ of the variance). The remaining 13 items, however, had a very good inter-item reliability (Cronbach's alpha $=.92$; see Appendix Table A10 for further details).

Science Fiction Hobbyism Scale. This scale was identical to that used in the Pilot Study. In Study 1, the scale had a very good inter-item reliability as well (Cronbach's alpha $=.92$; see Appendix Table A6 for more psychometric analyses).

Dependent variable / approval of mind upload. Our dependent variable had nine items that were averaged together. Example items are: 'The scientist acted in a morally correct fashion' and 'There was nothing wrong with the scientist's actions'. Four items were reverse coded (e.g., "The scientist should be punished for what he did'). The DV had a strong single factor structure and a good Cronbach's alpha (.89; for full listing of items and psychometric analyses, see the Appendix Table A2). Higher (or lower) scores indicate higher rates of approval (or disapproval) of the actions of the scientist, that is mind upload. Note that in the Pilot Study, higher scores indicated higher rates of disapproval. The difference in coding is due to issues of translating the DVs from English to Finnish.

Study 1 Results. One-way ANOVA showed that the experimental manipulation had no effect $(F(3,156)=1.45, p=$ n.s. $)$, indicating that the target of mind upload is irrelevant for condemning or not condemning the scientist's actions. We then continued by running a regression analysis with just the HEXACO personality dimensions and there were no significant associations with our DV (all $|t| s<1.65, p s=$ n.s.). We also ran a regression analysis with just Schwartz's value dimensions, finding that only the values of traditionalism were statistically significant $(B=-0.29$, $95 \%$ CI $[-0.51,-0.07])^{9}$

Thereafter we ran a multiple regression analysis similar to the one used in our Pilot Study (see Table 2 for full statistics). We first built a baseline model with age and gender as covariates; and then sequentially added covariates as follows. Second model: level of education and income. Third model: Religiosity Scale and Science Fiction Hobbyism scale. Fourth model: Moral Foundations Questionnaire as a whole. In the fifth and sixth models, we dropped all non-significant variables and added Schwartz's Traditionality, which however, was not significant.

The results of Study 1 suggest that, like in the Pilot Study, age is an explaining factor in condemning the scientist's actions, but only until the model is controlled for the MFQ variables. Furthermore, the gender effect, which was observed in this study (Models 1-2; Table 2) but not in the Pilot Study (sampled in a US population), disappeared after controlling for religiosity and science fiction hobbyism (Model 3; Table 2). We probed this further and found that the gender effect disappeared after

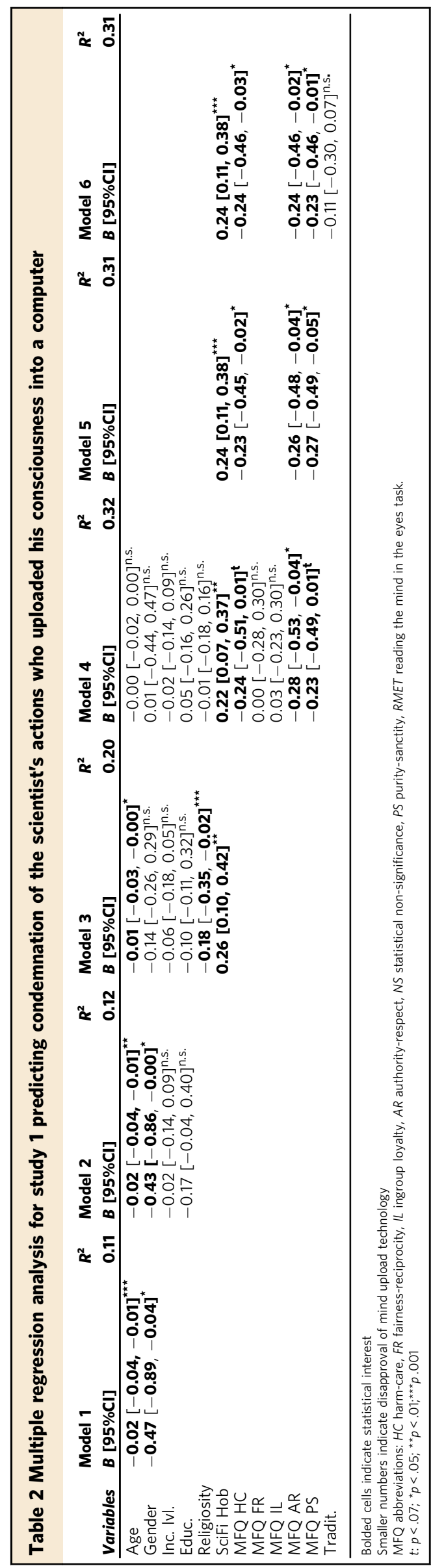


controlling for science fiction hobbyism, but not after controlling merely for religiosity. Thus, Finnish men and women are equally accepting / condemning of mind upload scenarios, but only if their cultural exposure to science fiction is held constant.

The effect of religiosity observed in the Pilot Study (Models 3-7; Table 1) was not observed in Study 1 (Table 2), where the effect disappeared after the MFQ variables were entered into the model. We further observed that the effect of religiosity was mediated by the MFQ sub-scales Authority and Purity. Most interestingly and most importantly, the effects of Science Fiction Hobbyism and Purity were consistently replicated in Study 1: Purity was associated with condemning mind upload, while Science Fiction Hobbyism in turn, was associated with approving mind upload-even when both variables along with religiosity were simultaneously present in the model.

Study 1 Discussion. Study 1 successfully replicated the main findings of our Pilot Study: Science Fiction Hobbyism was strongly associated with approval of mind upload technology and MFQ Purity orientation with condemning it. Furthermore, the results of Study 1 suggest that what really matters in terms of moral condemnation is the act of mind transfer-and not where the mind is transferred to. We also found a link between condemnation and the MFQ sub-scale Authority-Respect; but this finding could not be replicated in our subsequent Studies, and thus we concluded it was probably a false positive.

Furthermore, the effects of religiosity observed in the US sample were not replicated in the Finnish sample. This is not surprising considering US is among the most religious western countries, whereas Finland is among the most secular and atheistic ones. It seems prima facie that religion and religiousness have dissimilar meanings for Finns and Americans. However, considering that Purity orientation was triggered similarly in these two different samples with two culturally different populations, it is possible that the stimulus materials themselves trigger disgust reactions. According to Rozin et al. (1999), disgust is related to so-called body-envelope violations (see also Douglas, 1966), and indeed, in our story the nano-machines are injected into the bloodstream of the scientist. To rule out this possible idiosyncrasy as a confounding factor, we decided to replicate the study by altering the story (Study 2). Furthermore, according to Haidt and Graham (2007) and Rozin and colleagues (1999), purity concerns are associated with both the emotion of disgust and epistemic structures surrounding the perceived fate of the human soul (see also Horberg et al., 2009). This claim has also empirical backing: people with high levels of purity orientation are more likely to condemn suicides (Rottman et al., 2014). Thus, in our next Study, we decided to accommodate for this possible confound as well.

Study 1 also allowed us to rule out the effects of personality traits (Ashton and Lee, 2007, 2009) and value orientations (Schwartz, 2007; Myyry et al., 2009) on moral condemnation in our context. However, the fact that Honesty-Humility and other personality factors were unrelated to condemning mind upload was surprising, since at least the Honesty-Humility -factor has previously been linked to many recent findings in moral psychology (de Vries et al., 2017; Djeriouat and Trémolière, 2014).

\section{Study 2}

Study 2 was designed to rule out possible confounds in our stimulus materials and to control for individual differences in sensitivity towards death anxiety and condemnation of suicide. In the first version of our vignette, the scientist uses a needle to inject nano-machines into his bloodstream (this is a body-envelope violation and a possible disgust trigger; Rozin et al., 1999), after which his body falls to the ground completely limp, leaving it open whether he actually 'physically' dies or not (possible suicide confound, see Rottman et al., 2014). We changed the story in a manner that the scientist merely ingests the nano-machines in a capsule form. Furthermore, we used a $2 \times 2$ experimental set-up to investigate whether the body dying on a physical level [heart stops or the brain stops] impacts the condemnation of the scientist's actions. We also investigated whether giving participants information on how the transformation feels for the scientist once he is in the new platform has an impact on the results. We reasoned that information about the feelings associated with the transfer would make it salient that the scientist is, in fact, still alive after the transfer.

Since in our previous Studies we replicated Purity effects in two culturally different samples, we also wanted to explore the possibility that there is a deeper and more biological disgust component involved. To this end, in Study 2 we included the Three Domain Disgust Scale (TDDS; Tybur et al., 2009), given its strong ties to biology and evolutionary psychology. Furthermore, in a recent study, Laakasuo et al. (2017) showed that two of the three sub-components of TDDS are associated with deontological moral attitudes in different ways: pathogen disgust is associated with more utilitarian attitudes and sexual disgust with more deontological attitudes (whereas moral disgust was not associated with moral cognition at all; see also Laakasuo and Sundvall, 2016). Given this link between Sexual Disgust and deontological moral attitudes, we expected to find a similar link between Sexual Disgust and moral condemnation of mind upload. To sum up, in Study 2 we aimed to disentangle several confounds and probe deeper into possible explanatory biological and cultural factors.

\section{Method}

Participants and design. In total, 221 participants $(N=221 ; 114$ female; Age $_{M}=38.65 ; \mathrm{SD}=16.84$; Range $=18-80$ ) were recruited in the same location and using the same procedure as in Study 1. In Study 2, participants were offered $2.5 €$ for their participation.

After a non-intrusive recruitment procedure, the participants were escorted into our 'pop-up' laboratory located in the library (see Study 1 procedures). The participants then sat in front of a laptop computer, which randomized them into one of four conditions in a $2 \times 2$ factorial design (the experimenters were blind to the randomization).

Procedure and materials. We used the same procedure and software as in Study 1. The experiment in Study 2 started by randomizing the participant into one of four conditions. First, the participants filled in the Death Anxiety and Suicide Condemnation scales, after which they proceeded to fill in the same Science Fiction Hobbyism and Religiosity scales used in our previous Studies.

Next, participants read one of four vignettes, where the scientist transfers his consciousness onto a computer. As a result of this transfer, either the scientist's (1) brain activity stopped but his heart kept beating, or (2) both brain and heart activity ceased (first factor with two levels). The feelings of the scientist following the transfer were either (3) described or (4) not described (second factor with two levels). The story was otherwise identical to the one presented in the Pilot Study, with the exception that rather than injecting nano-machines into his body, the scientist ingests them in a capsule form. After reading the story, the participants responded to the dependent variables and demographic questions. Finally, they were debriefed and thanked by the research assistants. 
Three Domain Disgust Scale. This scale was created by Tybur and colleagues (2009) based on an evolutionary theoretical framework. The scale has 21 items and measures three different aspects of disgust sensitivity. The items are divided into three sub-scales of 7 items each, labeled (1) Moral Disgust, (2) Sexual Disgust and (3) Pathogen Disgust. Participants are instructed to think about how disgusted they would feel by specific statements. The items are anchored from ' 1 ' (not at all disgusting) to ' 7 ' (very disgusting). Example items for Moral, Sexual and Pathogen disgust, respectively, are: (1) 'Shoplifting a candy bar from a convenience store'; (2) 'Hearing two strangers having sex'; (3) 'Stepping on dog poop'. Higher scores on all of the sub-scales indicate pronounced disgust sensitivity. There are no reverse coded items. The subscale specific Cronbach's alpha values were $.88, .83$ and .83 for Moral Disgust, Sexual Disgust, and Pathogen Disgust, respectively.

The Death Anxiety Scale. This scale was developed by Templer and Ruff (1971), and it correlates strongly with anxiety disorders as well as other measures of fear of death. The original scale prompted dichotomous 'True / False' responses to 15 statements regarding death and dying. However, for statistical purposes, we anchored each item from ' 1 ' (strongly disagree) to '7' (strongly agree), and removed 8 of the original items to dampen possible mortality salience primes. The Cronbach's alpha value for our modified scale was .72. Example items are 'I fear dying a painful death.' and 'The thought of death seldom enters my mind' (reverse coded).

Suicide condemnation measure. We used a shorted four-item version of the Attitudes Towards Suicide Permissiveness sub-scale (Renberg and Jacobsson, 2003; Arnautovska and Grad, 2010) to avoid strong depression-related primes. The items we used were: (1) 'Suicide should be accepted as a solution to end an incurable suffering'; (2) There are situations where the only rational solution is suicide'; (3) 'I would consider the possibility of taking my own life if I were to suffer from a severe, incurable disease'; and (4) 'People should have the right to take their own lives'. All the items were anchored from '1' (strongly disagree) to '7' (strongly agree) and were averaged together such as higher scores indicate higher approval of suicide. The Cronbach's alpha value for this scale was .86 .

Science Fiction Hobbyism Scale. In the current Study, Cronbach's alpha was .89 (see Pilot Study 1 for full description).

Religiosity Scale. In the current Study, Cronbach's alpha was .91 (see Study 1 for full description).

Dependent variable/approval of mind upload measure. The scale was identical to the one used in Study 1 (Cronbach's alpha $=.91$; for more detailed psychometrics and item descriptions see Appendix Table A3). Higher scores indicate higher approval of the scientist's actions, that is, mind upload.

Study 2 Results. Two-way ANOVA showed that neither of the experimental manipulations had statistically significant effects on our DV (all $F s<1$ and all $p s=$ n.s.). This suggests that whether the body of the scientist dies 'partially' (brain activity ceases but heart keeps beating) or 'fully' (brain activity ceases and heart stops beating), or whether the feelings of the scientist after the mind upload are made salient, was irrelevant with respect to the participants' condemning of the scientist's actions. We then continued with a multiple regression similar to the one we conducted in our previous Studies (for full statistics see Table 3), ignoring the experimental structure of the data.

We again started by entering age and gender into a baseline model, and sequentially added further covariates as follows. Second model: Science Fiction Hobbyism scale. Third model: Suicide Condemnation and Death Anxiety scales. Fourth model: Moral Foundations Questionnaire as a whole. Fifth model: Dropped all non-significant variables. Sixth and seventh models: Added the Three Domain Disgust scales.

The results of Study 2 again show that gender differences in approval of mind upload scenarios depend on science fiction hobbyism (Models 1-2; Table 3). Furthermore, both Death Anxiety and Suicide Condemnation were associated with increased approval of mind upload (Model 3; Table 3). This suggests that mind upload is not seen as a form of suicide-this is the exact opposite of what could have been expected based on previous research (Rottman et al., 2014).

After controlling for the MFQ variables, only Death Anxiety remained statistically significant (Model 4; Table 3); in this model Purity and Harm-Care were the only significant MFQ sub-scales. After removing non-significant variables from the analysis (Model 5; Table 3), Purity and Harm-Care remained significant. After adding the Three Domain Disgust scale as a predictor (Models 5-7; Table 3), only the Sexual Disgust sub-scale, along with Purity and Harm-Care, were statistically significant in predicting the condemnation of mind upload. Thus, two different types of constructs associated with disgust (purity concerns and sexual disgust) were linked to condemnation of mind upload independently of one-another.

The results of Study 2 were consistent with our previous Studies despite the differences in the mind upload vignettes (scientist ingesting a capsule in Study 2 vs. injecting a needle in the previous Studies). We also asked participants how disgusting or "dirty" they felt the scientist's actions were, on a scale from 1 (not at all) to 7 (very). Across our Studies the mean values (SD in brackets) for these measures ranged between 2.9 (1.7; Pilot Study) and 2.7 (1.8; Study 2), indicating that there were only minor differences in disgust-ratings between the two vignettes (needle vs. ingestion). This suggests that the "needle" version of the story did not elicit disgust to an extent that would have explained the results.

Study 2 Discussion. The results of Study 2 show that condemnation of the use of mind upload technology is not related to either condemnation of suicide or to the potentially disgusteliciting element of needle-injection in our previous vignettes. Both suicide condemnation and death anxiety were linked to approval of mind upload; thus, uploading one's mind onto a computer is most likely not viewed as 'death' or 'dying'. Instead, the results suggest that mind upload is seen more as a way of lifeextension than death of one's previous body (or soul); both scales measuring anxiety for death and suicide condemnation were associated with more approval of mind upload technology.

We have now consistently observed the effects of Purity and Science Fiction Hobbyism in three independent studies. In Study 2, also Sexual Disgust predicted condemning mind upload even after controlling for the effects of science fiction hobbyism and purity. This finding is in line with previous research linking sexual disgust to utilitarian and deontological judgements (Laakasuo et al., 2017). We also replicated the effect of the MFQ Harm-Care sub-scale; this effect, however, was absent in the US data (Pilot Study), and not replicated in Study 3, leading us to conclude it was probably a false positive. As our final step in the current set of studies, we sought to replicate the main effects of 


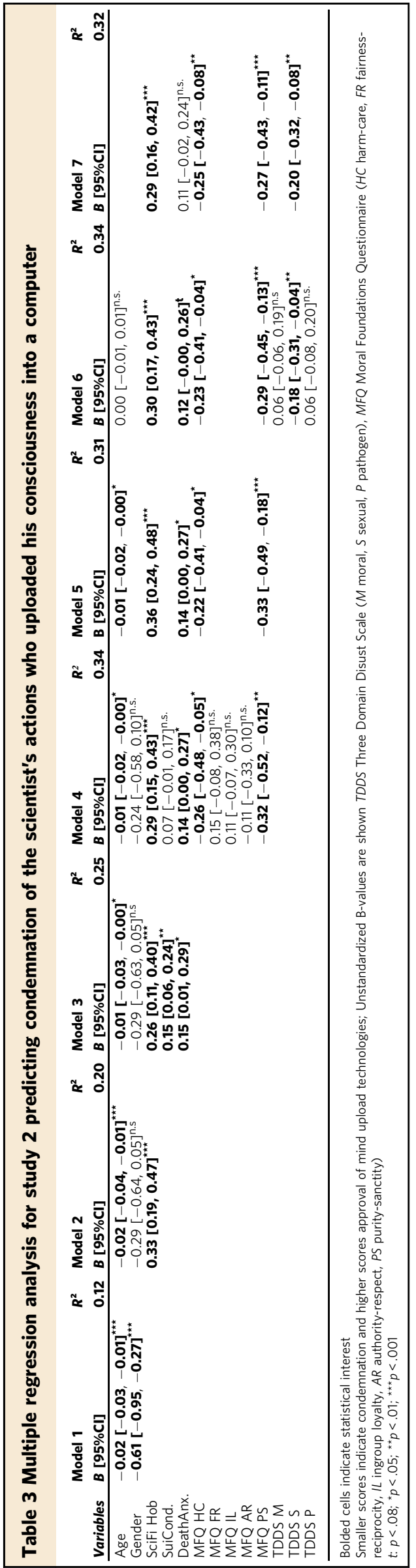

Study 2 with a larger and more varied sample to ascertain the effects found for Sexual Disgust were not a false positive.

\section{Study 3}

The main aim of Study 3 was to replicate the effects of Sexual Disgust and Purity in a different population, and to gain more confidence in the general pattern of results found across our previous laboratory studies. Study 3 was an online correlational study sent out to several Finnish student associations throughout the country.

\section{Method}

Participants and design. In total, 391 respondents opened the first page of a correlational Internet questionnaire and $303(N=303$; 221 female) completed the questionnaire adequately. Participants were on average 25.7 years old $(\mathrm{SD}=5.38$; Range $=19-55)$ and were recruited with emails sent to several university student associations located across Finland. Participants were offered a chance to enter their email address on a separate form to participate in a movie ticket raffle $(50 \times 10 €)$.

Procedure and materials. After giving informed consent, the participants filled in the Three Domain Disgust scale, Science Fiction Hobbyism Scale and the Moral Foundations Questionnaire. Subsequently, they read the same science fiction story as in Study 2 and gave their responses to the dependent variables. Finally, they were debriefed and offered the option of entering their email addresses on a separate form if they wanted to participate in a raffle for movie tickets. There were missing values for two participants in our DV and the MFQ Purity sub-scale. These missing values were imputed using STATA 13's multinormal distribution imputation strategy (for detailed descriptions of the materials see Studies 1 and 2.)

Study 3 Results. We ran a regression analysis by first entering the MFQ Purity and Harm-Care, and the Science Fiction Hobbyism Scale into the model at the same time $\left(R^{2}=.09, F(3,299)=9.98\right.$, $p<.001)$. Consistent with our previous Studies, the effects of Purity $(B=-0.21,95 \%$ CI $[-0.35,-0.07], p<.01)$ and Science Fiction Hobbyism $(B=0.22,95 \%$ CI $[0.10,0.34], p<.001)$ were successfully replicated and statistically significant predictors of our DV. However, the effects of harm-care were not replicated $(B=-0.08,95 \%$ CI $[-0.22,0.06], p=$ n.s. $)$. We thus dropped the harm-care sub-scale from the analysis and added the Sexual Disgust sub-scale into the model. In this final model $\left(R^{2}=.09, F\right.$ $(3,299)=9.98, p<.001)$, all three variables were statistically significant at the same time: Purity: $(B=-0.14,95 \%$ CI $[-0.28$, $-0.00], p<.05)$; Science Fiction Hobbyism: $(B=0.21,95 \% \mathrm{CI}$ $[0.10,0.33], p<.001)$; TDDS Sexual Disgust: $(\mathrm{B}=-0.17,95 \% \mathrm{CI}$ $[-0.28,-0.05], p<.01)$. Both Purity and Sexual Disgust were separately related to the condemnation of mind upload, whereas Science Fiction Hobbyism predicted its approval.

Study 3 Discussion. In Study 3, we successfully replicated the effects of Sexual Disgust and MFQ Purity, as both predicted negative judgments or condemnation of the use of mind upload technology while controlling for each other's effects. Furthermore, we did not replicate the effects of MFQ harm-care, which suggests that the effect found in our previous Studies is likely to be a false positive. It is also possible that these effects were not replicated due to more "noisy data" collected online.

\section{General Discussion}

Across four studies, we consistently showed that Purity orientation from Haidt's Moral Foundation's Questionnaire (Haidt and 
Graham, 2007; Koleva et al., 2012) is positively associated with condemnation of the act of transferring one's consciousness onto a new object (in a hypothetical scenario based on a story by Moravec, 1988). Furthermore, in two of our studies we found a link between Sexual Disgust and condemning mind upload, which suggests that a biological component might be involved. We also found consistent age effects (older people condemn mind upload more than younger people), which together with our Science Fiction Hobbyism Scale imply that cultural factors, such as exposure to the ideas of consciousness transfer from young age through books, films and pop culture is also an important factor. In other words, familiarization with transhumanist themes together with biological components related to disgust and purity seem to play a significant role in determining whether people condemn or approve of mind upload technology.

Moreover, we showed that the main object of condemnation is the actual act of transferring one's consciousness away from one's self (Study 1), since the experimental factors controlling for the platform or the "target" of the transfer were all non-significant. In Study 2, we ruled out death and disgust primes as possible explanations for the results. The possible perceived death of the scientist was controlled experimentally; and we further changed the stimulus material not to include so-called 'body-envelope violations', which, according to Rozin and colleagues (1999), are salient disgust primes.

One of the more intriguing pieces of our results is the one that relates to Death Anxiety. In Study 2 we controlled for individual differences in death anxiety (Templer and Ruff, 1971) and suicide condemnation (Renberg and Jacobsson, 2003; Arnautovska and Grad, 2010), both of which-contrary to our initial expectationspredicted higher approval of mind upload technology. It is quite interesting that despite the scientist losing his actual physical body in the vignettes, his actions were not perceived as dying or as being suicidal. Throughout human history and cultures, there are myths about fountains of youth and stories about becoming immortal. It is noteworthy that these same motivations, dreams or intuitive existential and moral concerns surface in postmodern technological contexts. From this perspective, our findings link back to the perennial questions driving our civilizations; the results do seem reasonable since people who are anxious about death probably find the idea of extending life, or even transcending death, comforting (O'Connell, 2017; Kurzweil, 1999, 2004).

To our knowledge, we have now for the first time empirically shown that approval of mind upload technology aligns with the hopes and wishes of central transhumanist advocates (O'Connell, 2017) who actually want to develop these technologies to achieve immortality. Perhaps the preference towards attaining immortality is even more widely shared than previously imagined; and if this were the case, future mind upload technologies might be of great interest to the general population. However, many questions still remain unanswered, such as whether people view mind upload as 'merely' life-extension or actual immortality, and whether only those who want to be immortal approve of mind upload. Further research is needed to answer these questions.

Across our studies, we found that pathogen disgust-when measured both by the PVD (Duncan et al., 2009) and the TDDS (Tybur et al., 2009)—was not associated with condemning mind upload. However, sexual disgust was strongly associated with condemnation of the mind upload, along with MFQ Purity, which is a more abstract and indirect measure of disgust (Haidt and Graham, 2007; Koleva et al., 2012). These findings resonate with a recent study by Laakasuo et al. (2017), where sexual disgust was strongly associated with deontological (as opposed to utilitarian) preferences in solving high conflict moral dilemmas. Perhaps what is actually 'condemned' in the context of mind upload is the act of 'instrumentalizing' or objectifying the human consciousness or 'soul'; in deontological intuitions, condemnation is typically related to objectifying humans or using them as instruments. Sexual disgust might thus be, in an abstract sense, related to condemnation of mind upload technology, because the mind or "soul" is the "essence" of what it is to be a person (from a folk psychological perspective). Furthermore, some of the items used in the sexual disgust sub-scale describe acts and deeds that objectify the person filling in the questionnaire (e.g.,'Finding out that someone you do not like has sexual fantasies about you')the same cue that is related to deontological cognition and Kant's categorical imperative.

There are also interesting parallels between our current studies and previous research showing women are more deontologically oriented and more easily sexually disgusted than men (Tybur et al., 2009; Laakasuo et al., 2017; Capraro and Sippel, 2017; Fumagalli et al., 2010). Perhaps people with transhumanistic leanings also find utilitarian approaches to moral dilemmas more appealing than deontological ones. Thus, the gender differences we observed could also be explained by general deontological moral preferences; we think this would be an interesting direction to take in future research.

Also the many null-findings in our studies are revealing. We discovered that HEXACO, Schwartz's Value Orientations, theory of mind capacity, and rational intuition were not related to moral condemnation of this technology. This implies that the effects of disgust sensitivity and purity are not explained away by other immediately 'obvious' factors (or 'usual suspects'), further strengthening our results and interpretations.

Like all behavioral studies, ours suffers from a standard set of limitations in laboratory or Internet questionnaires. Our respondents were not a purely random sample representing the general population. Instead, they were likely more curious and open minded than the population average, having volunteered to participate in scientific research. Our participants were also younger than the Finnish population average. Nonetheless, by also recruiting participants from a large public library-which was the best location we could think of to obtain a representative sample of the general population-we significantly mitigated the above concerns. Survey-based studies utilizing self-report measures are also biased by a mixture of positive response biases and demand characteristics. However, since our core results were replicated across four studies (both online and off-line and in two different cultures), this seems quite unlikely.

Another limitation in our studies relates to the representativeness of our samples. Across our studies our participants were self-selected people, and our samples might have been biased towards, for example, those people who were curious and/or generally willing to contribute to science. Thus, the generalization of our results is not clear and the findings need to be interpreted with some caution. However, we note that this is an inherent problem in any research involving human participants, and not specific to our studies. Moreover, in most psychological research the participants are generally young female students recruited in a university campus-our methods for sampling participants are arguably much more rigorous than merely using university students as participants.

Across our statistical models, the best explanatory effect was around $33 \%$; this means that at best we were able to explain one third of the variance in our dependent (response) variable. Conversely, it means that two thirds of the variance was left unexplained. While this may sound like a high amount, we note that effect sizes of around $20-30 \%$ are considered very high in psychological sciences-modeling human behavior, attitudes, and individual differences is a very 'noisy' process.

Finally, in our studies we focused on one specific mind upload technology, wherein the brain is destroyed as a consequence (a 
'Moravec transfer'; Moravec, 1988). This was a conscious methodological decision to avoid issues related to multiple possible simultaneous identities (Chalmers, 2010). There have been suggestions in transhumanist literature that copying the brain without destroying it might be possible. However, several authors argue that any kind of physical body is only a temporary solution and offers more limited opportunities for improvement and adaptation than a 'substrate-independent mind', and thus a destructive upload is preferable (for an overview of the theme see International Journal of Machine Consciousness, Volume: 4, Number: 1 [June 2012], Special Issue on Mind Uploading; and for more specific argumentation, see Koene, 2012)

At the time of writing the most realistic techniques for mapping the human brain connectome require the brain to be cut into thin slices for proper imaging (for example, see the startup Nectome with plans to preserve brains in near future, so that they can be uploaded when the necessary technology becomes available $^{10}$ ). Regardless of how mind upload technologies actually develop in the future, it is still important to understand people's perceptions and preferences concerning their use. Thus, different descriptions of achieving mind transfer offer a fruitful line for future research on human perceptions of postmodern technologies. Furthermore, as stated in the introduction, even if these technologies do not become reality within the next 20 years, we feel that the ethics and moral psychology regarding the implications of the technologies need to be discussed well in advance, due to their obviously serious implications for human societies. Digital technologies develop at exponential speeds, and given that the first breakthroughs have already been made (a functional copy of a rat's sensory cortex has already been created), we should be prepared to have a serious ethical discussion about the use of these technologies sooner rather than later. At the moment the EU is funding the development of these technologies with over 1 billion euros, and crucial advancements have already been made.

Future research should also look into the question of why sexual disgust sensitivity and purity orientation predict negative attitudes towards mind upload technology. Are these constructs possibly associated with rejecting "human enhancement" technologies in general, and if so, why? The current results, alongside those of Laakasuo et al. (2017) linking sexual disgust to deontological moral decisions, might suggest that moral cognition is a product of sexual- instead of group selection (see also Miller, 2000, 2007); hence we should expect to find some meaningful gender differences in future studies on moral cognition in postmodern contexts. Jonathan Haidt, who is the main developer of MFQ (Haidt and Graham, 2007; Koleva et al., 2012), has argued on behalf of group-selection models in defense of his model (Wilson, 2002; Haidt, 2006, 2007). If Haidt is correct, our data hints at an evolutionary mechanism behind moral cognition that combines both group-level and sexual selection mechanisms. This by no means solves the puzzle; but we nonetheless argue for including several disgust sensitivity measures in future research dealing with moral issues in post-modern technological environments.

Since mind upload technology has obvious theological implications (Hughes, 2007; Geraci, 2010), future studies should also focus on cross-cultural and cross-religious comparisons. There might be differences in attitudes and general approval between, for example, Eastern (e.g., Buddhist, Hindu), and Western (e.g., Christianity) cultures and religions. Moreover, the Mormon Transhumanist Association is one of the older advocates of mind upload technology and both it and the Christian Transhumanist Association claim growing memberships. This is interesting, given that sexual disgust and moral purity orientation are linked to more conservative religious and political positions, as well as condemning mind upload, as we have shown. There are also several other topics for future research, such as measuring individual differences in preferences to become immortal across cultures and religions; or even among users of psychedelic substances, which apparently reduce feelings of anxiety or stress towards death (Dutta, 2012).

On a related note, our results are interestingly in line with recent statements made by Leon Kass, who was one of the leading figures on the U.S. President's Council on bioethics. Kass condemned the use and development of transhumanist technologies by and large based on his disgust reaction (O'Connell, 2017; Kass called his reaction 'Wisdom of Repugnance'). This highlights the major societal relevance of our studies by confirming the existing prejudices. Moreover, our results extend the implications of these prejudices by pinpointing their bio-cognitive origins to be in the sexual disgust system and intuitions about purity norms, rather than pathogen based or moral disgust.

\section{Conclusions}

In summary, we successfully showed that natural dualismpeople's intuitive tendencies to separate mind from matter-is relevant in modern day contexts where moral implications of new technologies are being evaluated. Furthermore, we successfully linked, in four studies, this condemnation tendency to factors associated with disgust sensitivity (MFQ Purity and Sexual Disgust). We found that Science Fiction Hobbyism, Death Anxiety and Suicide Condemnation are linked to approval of mind upload. We also successfully ruled out possible idiosyncrasies associated with our stimulus materials, and eliminated multiple alternative explanations common in the study of moral cognition (Schwartz's Values, HEXACO Personality Inventory, ToM, and rational tendencies). Future studies in moral cognition should look more carefully into associations between purity, sexual disgust and adoption of new technologies. Our findings are highly relevant also because they reflect the attitudes and reactions on future technologies taking place on high governmental levels, such as the U.S. President's Council on Bioethics. Understanding moral cognition in this context could be one of the most important issues when it comes to guiding future norm-setting with respect to new technologies.

Received: 1 November 2017 Accepted: 21 May 2018

Published online: 10 July 2018

\section{Notes}

1 Naturally, ritualistic purity is not the only aspect of social life influencing one's afterlife fate in major Indian religions. There are, for example, many historical factors that also influence individuals' social obligations, but these are beyond the scope of our current studies (Werner, 1988). However, the eightfold path in Buddhism highlights the importance of living mindfully in a social setting today, here and now, which is in line with our main argument: The fate of the soul is influenced by worldly affairs-no matter what they might be.

2 https://www.sciencealert.com/a-new-start-up-wants-to-transfer-your-consciousnessto-an-artificial-body-so-you-can-live-forever

3 http://www.dailymail.co.uk/sciencetech/article-2879803/The-scientists-planningupload-brain-COMPUTER-Research-allow-inhabit-virtual-worlds-live-forever.html

4 https://www.sciencealert.com/scientists-put-worm-brain-in-lego-robot-openwormconnectome

5 https://www.nature.com/news/fragment-of-rat-brain-simulated-in-supercomputer1.18536

6 http://lesswrong.com/lw/nun/superintelligence_via_whole_brain_emulation/

7 LessWrong is certainly not the only online community discussing these issues; however, it is an open Internet community with strong transhumanistic leanings and therefore is a window into the community of people who wish to discuss these matters actively

8 Shenhav, Rand and Greene (2012) have found that intuitive thinking style and religiosity are associated. We therefore also investigated if the REI Experientality 
Scale was associated with Religiosity also in our study, but found no evidence for it ( $r$ $=.04, p=$ n.s.) in our data.

9 Note that we have used unstandardized B-values throughout our manuscript. This is due to ease of interpretation: our dependent variables, as well as most independent variables, were consistently coded from 1 to 7 . Unstandardized $B$-values can be interepreted as follows: For every one unit increase in our independent (predictor) variables, the dependent variable increase by $B$.

10 https://www.technologyreview.com/s/610456/a-startup-is-pitching-a-minduploading-service-that-is-100-percent-fatal/

\section{References}

Anttonen V (1994) Transcending bodily and territorial boundaries. Reconceptualizing shamanism as a form of religion. Shaman 2(2):1-9

Arnautovska U, Grad OT (2010) Attitudes toward suicide in the adolescent population. Crisis 31:22-29

Ashton MC, Lee K (2007) Empirical, theoretical, and practical advantages of the HEXACO model of personality structure. Personal Social Psychol Rev 11 (2):150-166

Ashton MC, Lee K (2009) The HEXACO-60: A short measure of the major dimensions of personality. J Pers Assess 91(4):340-345

Atran S (2002) In Gods we trust. Oxford University Press, Oxford

Baron-Cohen S, Wheelwright S, Hill J, Raste Y, Plumb I (2001) The 'Reading the Mind in the Eyes' test revised version: a study with normal adults, and adults with Asperger syndrome or high-functioning autism. J Child Psychol Psychiatry 42(2):241-251

Bering JM (2006) The folk psychology of souls. Behav Brain Sci 29(5):453-462

Bloom P (2004) Descartes' baby: how the science of child development explains what makes us human. Basic Books, New York

Bonnefon JF, Shariff A, Rahwan I (2016) The social dilemma of autonomous vehicles. Science 352(6293):1573-1576

Bostrom N (2014) Superintelligence. Oxford University Press, Oxford

Boyer P (2001) Religion explained. Basic Books, New York

Cappuccio ML (2017) Mind-upload. The ultimate challenge to the embodied mind theory. Phenomenol Cogn Sci 16(3):1-24

Capraro V, Sippel J (2017) Gender differences in moral judgment and the evaluation of gender-specified moral agents. Cogn Process 18(4):399-405

Carrier R (2014) On the historicity of Jesus. Phoenix Press, Sheffield

Chalmers D (2010) The singularity: a philosophical analysis. J Conscious Stud 17:7-65

Chapman HA, Anderson AK (2014) Trait physical disgust is related to moral judgments outside of the purity domain. Emotion 14(2):341-348

Chappie (2015) Directed by Neill Blomkamp [Film]. MRC \& Kinberg Genre.

Curtis V (2013) Don't look, Don't touch. Oxford University Press, Oxford

de Vries RE, Pathak RD, van Gelder JL, Singh G (2017) Explaining unethical business decisions: the role of personality, environment, and states. Pers Individ Dif 117:188-197

Djeriouat H, Trémolière B (2014) The dark triad of personality and utilitarian moral judgment: the mediating role of honesty/humility and harm/care. Pers Individ Dif 67:11-16

Douglas M (1966) Purity and danger: an analysis of concepts of pollutionÿ and taboo. Routledge, London

Duncan S, Schaller M, Park J (2009) Perceived vulnerability to disease: development and validation of a 15 -item self-report instrument. Pers Individ Dif 47:541-546

Durkheim E (1915) Elementary forms of religious life.Allen \& Unwin, London

Dutta V (2012) Repression of death consciousness and the psychedelic trip. J Cancer Res Ther 8(3):336

Edmonds RE (2015) Imagining the afterlife in Greek religion. In: Esther E, Kindt J (eds) Oxford handbook of ancient Greek religion. Oxford University Press, Oxford and New York, pp 551-563

Eliade M (1964) Shamanism: archaic techniques of ecstasy. Princeton University Press, London

Frazer J (1922) Golden bough. McMillan, New York, | 1890

Fumagalli M, Vergari M, Pasqualetti P, Marceglia S, Mameli F, Ferrucci R, MrakicSposta S, Zago S, Sartori G, Pravettoni G, Barbieri S, Cappa S, Priori A (2010) Brain switches utilitarian behavior: does gender make the difference? PLoS ONE 5(1):e8865

Geraci R (2010) Apocalyptic AI: visions of heaven in robotics, artificial intelligence, and virtual reality. Oxford University Press, Oxford and New York

Gray K, Young L, Waytz A (2012) Mind perception is the essence of morality. Psychol Inq 23(2):101-124

Greene J (2014) Moral tribes. Penguin, New York

Graham J, Nosek BA, Haidt J, Iyer R, Koleva S, Ditto PH (2011) Mapping the moral domain. J Pers Soc Psychol 101(2):366-385

Haidt J (2006) The happiness hypoa naturalistic approachthesis: finding modern truth in ancient wisdom. Basic Books, New York

Haidt J (2007) The new synthesis in moral psychology. Science 316 (5827):998-1002
Haidt J (2012) The righteous mind: why good people are divided by politics and religion. Pantheon, New York

Haidt J, Graham J (2007) When morality opposes justice: Conservatives have moral intuitions that liberals may not recognize. Soc Justice Res 20(1):98-116

Haslam N, Loughnan S (2014) Dehumanization and infrahumanization. Annu Rev Psychol 65:399-423

Homer, Rieu EV (1959) The odyssey. Vintage Books, New York

Horberg EJ, Oveis C, Keltner D, Cohen AB (2009) Disgust and the moralization of purity. J Pers Soc Psychol 97(6):963-976

Horton JJ, Rand DG, Zeckhauser RJ (2011) The online laboratory: conducting experiments in a real labor market. Exp Econ 14:399-425. https://doi.org/ $10.1007 / \mathrm{s} 10683-011-9273-9$

Hughes J, (2007) The compatibility of religious and transhumanist views of metaphysics, suffering, virtue and transcendence in an enhanced future Glob Spiral 8(2):1-40http://ieet.org/archive/20070326-Hughes-ASU-H+Religion. pdf. Accessed 1 Apr 2018

Johnson P (2002) Secrets, gossip and Gods: the transformation of Brazilian candomble. Oxford University Press, Oxford and New York

Jürgensmeyer M, Roof WC (2011) Encyclopedia of global religion. SAGE Publications, New York

Koene RA (2012) Embracing competitive balance: the case for substrateindependent minds and whole brain emulation. In: Eden A, Søraker J, Moor J, Steinhart E (eds) The singularity hypothesis: a scientific and philosophical assessment. Springer, New York, pp 241-267

Koleva SP, Graham J, Iyer R, Ditto PH, Haidt J (2012) Tracing the threads: how five moral concerns (especially Purity) help explain culture war attitudes. J Res Pers 46(2):184-194

Kurzweil R (1999) The age of spiritual machines. Penguin, New York

Kurzweil R (2004) Fantastic voyage. Rodale Inc, Emmaus, PE

Laakasuo M, Köbis N, Palomäki J and Jokela M (2017) Money for microbespathogen avoidance and out-group helping behaviour. Int J Psychol. https:// doi.org/10.1002/ijop.12416.

Laakasuo M, Sundvall J (2016) Are utilitarian/deontological preferences unidimensional? Front Psychol 7:1228

Laakasuo M, Sundvall J, Drosinou M (2017) Individual differences in moral disgus do not predict utilitarian judgments, sexual and pathogen disgust do. Sci Rep 7:45526

Lee K, Ashton MC (2004) Psychometric properties of the HEXACO personality inventory. Multivar Behav Res 39(2):329-358

Lindeman M, Svedholm-Häkkinen AM, Lipsanen J (2015) Ontological confusions but not mentalizing abilities predict religious belief, paranormal belief, and belief in supernatural purpose. Cognition 134:63-76

Mark J (2016) Egyptian book of the dead. Ancient History Encyclopedia, London

McEvilley T (2002) The shape of ancient thought: comparative studies in Greek and Indian philosophies. Allworth Press and the School of Visual Arts, New York

Melson GF, Kahn Jr PH, Beck A, Friedman B (2009) Robotic pets in human lives: Implications for the human-animal bond and for human relationships with personified technologies. J Social Issues 65(3):545-567

Miller G (2000) The mating mind. Random House, New York

Miller G (2007) Sexual selection for moral virtues. Q Rev Biol 82(2):97-125

Moravec H (1988) Mind children: the future of robot and human intelligence. Harvard University Press, Harvard

Moscovici S (2001) Social representations: essays in social psychology. NYU Press, New York

Myyry L, Siponen M, Pahnila S, Vartiainen T, Vance A (2009) What levels of moral reasoning and values explain adherence to information security rules? An empirical study. Eur J Inf Syst 18(2):126-139

Narby J (2005) Intelligence in nature: an inquiry into knowledge. Penguin, New York

O'Connell M (2017) To be a machine. Granta, London

Pacini R, Epstein S (1999) The relation of rational and experiential information processing styles to personality, basic beliefs, and the ratio-bias phenomenon. J Pers Soc Psychol 76(6):972-987

Parker R (1995) Early orphism. In: Powell A (ed) The Greek world. Routledge, New York, pp 483-510

Paolacci G, Chandler J, Ipeirotis PG (2010) Running experiments on Amazon mechanical turk. Judgm Decis Mak 5(5):411-419

Petrovic A, Petrovic I (2016) Inner purity and pollution in Greek religion: volume I: early Greek religion. Oxford University Press, Oxford

Pigliucci M (2014) Mind-uploading: a philosophical counter-analysis. In: Blackford $\mathrm{R}$, Broderick D (eds) Intelligence unbound: the future of uploaded and machine minds. Wiley-Blackwell, Oxford, pp 119-130

Renberg ES, Jacobsson L (2003) Development of a questionnaire on attitudes towards suicide (ATTS) and its application in a Swedish population. Suicide Life-Threat Behav 33(1):52-64

Rottman J, Kelemen D, Young L (2014) Tainting the soul: Purity concerns predict moral judgments of suicide. Cognition 130(2):217-226 
Rozin P, Haidt J, McCauley CR (1999) Disgust: the body and soul emotion. In: Dalgleish T, Powers M (eds) Handbook of cognition and emotion. Wiley, New York, pp 429-445

Schwartz SH (2003) A proposal for measuring value orientations across nations in Questionnaire Development Report of the European Social Survey http:// www.europeansocialsurvey.org/docs/methodology/core_ess_questionnaire/ ESS_core_questionnaire_human_values.pdf. Accessed 30 July 2017.

Schwartz SH (2007) Universalism values and the inclusiveness of our moral universe. J Cross Cult Psychol 38(6):711-728

Severson RL, Carlson SM (2010) Behaving as or behaving as if? Children's conceptions of personified robots and the emergence of a new ontological category. Neural Netw 23(8):1099-1103

Shenhav A, Rand DG, Greene JD (2012) Divine intuition: cognitive style influences belief in God. J Exp Psychol: General 141(3):423

Sperber D (1996) Explaining culture: a naturalistic approach. Blackwell, Cambridge, MA

Tegmark M (2017) Life 3.0. Random House, New York

Templer DI, Ruff CF (1971) Death anxiety scale means, standard deviations, and embedding. Psychol Rep 29(1):173-174

Tooby J, Cosmides L (2005) Conceptual foundations of evolutionary psychology. In: Buss D (ed) The handbook of evolutionary psychology. Wiley, Hoboken, NJ, pp 5-67

Transcendence (2014) Directed by Wally Pfister [Film]. Alcon Entertainment, DMG Entertainment \& Straight Up Films.

Tybur JM, Lieberman D, Griskevicius V (2009) Microbes, mating, and morality: individual differences in three functional domains of disgust. J Pers Soc Psychol 97(1):103-122

Tylor EB (1974) Primitive culture: researches into the development of mythology, philosophy, religion, art and custom. Gordon Press, New York

Wilson DS (2002) Darwin's cathedral. Oxford University Press, Oxford

Wallach W, Allen C (2008) Moral machines: teaching robots right from wrong. Oxford University Press, Oxford and New York

Ward AF, Olsen AS, Wegner DM (2013) The harm-made mind: observing victimization augments attribution of minds to vegetative patients, robots, and the dead. Psychol Sci 24(8):1437-1445

Waytz A, Gray K, Epley N, Wegner DM (2010) Causes and consequences of mind perception. Trends Cogn Sci 14(8):383-388

Werner K (1988) Indian concepts of human personality in relation to the doctrine of the soul. J R Asiat Soc 120(1):73-97

Wright R (2009) The evolution of God. Little, Brown \& Company, New York

Zeyl DJ (2009) Visualizing platonic space. In: Mohr R, Sanders K, Sattler B (eds) One book, the whole universe: Plato's Timaeus today. Parmenides Publishing, Las Vegas, pp 117-129

\section{Data availability}

The datasets generated and analyzed during the current study are available from Figshare.com (DOI: 10.6084/m9.figshare.6016145) collection. This project would not have been possible without a generous grant provided by Jane and Aatos Erkko Foundation to study the moral interactions between humans and AI (www.moim.fi and www.jaes.fi). MD would like to give special thanks to Tiina and Antti Herlin foundation for supporting her PhD work, during which she could collaborate with the 'Moralities of Intelligent Machines' research team. ML would also like to thank Apophenia for providing inspiration. All authors are members of the Moralities of Intelligent Machines research team (www.moim.fi). Principal investigator: Michael Laakasuo.

\section{Author contributions}

: ML conceived the study idea together with MD. ML compiled the first study. The first study was run by ML and JP. The follow-up studies were developed in collaboration with ML, MK, AK, MD and JP. Laboratory studies were programmed by ML with Python. Laboratory data were collected by JP, MK, NL, JH and AK. The initial manuscript was written up by ML and proofread, commented and edited by JP, MK and MD. The appendix was written and compiled by AK. All data were analyzed by ML. Analyses were double checked by AK.

\section{Additional information}

Supplementary information: The online version of this article (https://doi.org/10.1057/ s41599-018-0124-6) contains supplementary material, which is available to authorized users.

Competing interests: The authors declare no competing interests.

Reprints and permission information is available online at http://www.nature.com/ reprints

Publisher's note: Springer Nature remains neutral with regard to jurisdictional claims in published maps and institutional affiliations.

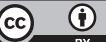

Open Access This article is licensed under a Creative Commons Attribution 4.0 International License, which permits use, sharing, adaptation, distribution and reproduction in any medium or format, as long as you give appropriate credit to the original author(s) and the source, provide a link to the Creative Commons license, and indicate if changes were made. The images or other third party material in this article are included in the article's Creative Commons license, unless indicated otherwise in a credit line to the material. If material is not included in the article's Creative Commons license and your intended use is not permitted by statutory regulation or exceeds the permitted use, you will need to obtain permission directly from the copyright holder. To view a copy of this license, visit http://creativecommons.org/ licenses/by/4.0/

(C) The Author(s) 2018

\section{Acknowledgements}

We thank Kaj Sotala from Foundational Research Institute for writing the first draft of our stimulus material, as well as Elmeri Laitinen and Nina Lukin for helping with data 